\title{
A Traditional Novel Approach for Skill Enhancement of Teaching - Learning Process in Engineering Education
}

\author{
Srinivas Aluvala, \\ Dept. of Computer Science and Engineering, \\ Dept. of Electrical and Electronics Engineering \\ SR Engineering College \\ Warangal, India \\ e-mal:srinu_aluvala@yahoo.com
}

\author{
Soumya Pothupogu \\ Dept. of Electrical and Electronics Engineering \\ SR Engineering College \\ Warangal, India \\ e-mal:soumyanelson@gmail.com
}

\begin{abstract}
In the modern day of technological competitiveness where world is demanding more technological developments which need to meet the present scenario problems. There is an urgent need of skilled engineers, as of now this need is not fulfilled by our engineering educational programs. Because there is a large gap between the educational structure and the societal demands, this has to be bridged by restructuring the engineering education. With this paper we come up with an approach of restructuring the engineering educational programs curriculum that bridge the gap and steer up the skills in the engineering students. An engineer should be basically a problem solver, who should own the capability to analyze and evaluate the problems arise in the society, at present we are in dire need of such engineers for the societal up gradation. In this paper, our view of initial attempt to restructure the curriculum of engineering education based on traditional age old learning will be shared. We evaluate student learning outcomes based on the practical assignment assessment results and their success in the implementation. With minor modifications in the present system and including the best of traditional year wise learning approach in
\end{abstract}

\footnotetext{
Srinivas Aluvala,

Dept. of Computer Science and Engineering,

Dept. of Electrical and Electronics Engineering

SR Engineering College

Warangal, India

e-mal:srinu_aluvala@yahoo.com
}

engineering education can bring a radical change, create greater impact on students to make them industry ready and problem solvers of society.

Keywords-Technological competitiveness; Skilled Engineers; Problem Solvers; Restructuring curriculum; Societal demands;

\section{Introduction}

In the present scenario of engineering education, there exist only theoretical evaluations with zero practicals approach. A student in return is worried about his grades, not on the knowledge accquisation as the present day assessment is based on bookish knowledge i.e. theoretical evaluation. As a result of this the present engineering programs are unable to make problem sloving engineers.

All the private engineering colleges affiliated to various universities, implementing the curriculm of semester system. Where the conceptual assessment is lacking in the process of assessment and skill base in purview of societal need is not met. The semester system on contrary is not imparting the knowledge and learning skills what they ought to.

The assessment carried out is mere theoretical and least importance is given for practical skills. The framework of the syllabus is mainly aimed at the historical developments and the applicability's are of least preference. The students sometimes find difficulty in finding the real time applications of their 
courses. Based on these the students are most of the times seeking the help of local publications that provide a readymade solutions for their end exam questionnaires. Knowledge acquisition, learning and skill development is not at all found in this but the grades are obtained. This causes hindrance to practical evaluation which reflects on the unemployment.

Moreover the practical sessions are being performed with a trainer kit which doesnot give an emphasis on the components used and the circuitry. The projects are being done with the help of agencies (buying projects).

\section{Age Old Traditional System (year Wise System)}

All the intellectuals who are the backbones of the society have studied in the year wise course structure. They had no recourses of the present times like Internet, e Books, etc., still their skill and knowledge are laudable. Their zeal to acquire knowledge and skill made the present world what it is now.

They too had certain drawbacks due to lack of internal assessments, practical resources for hands on experience etc., Their problems paved a way for the semester structure, which is rather emphasizing on theoretical evaluations. With slightest modifications we can incorporate the skill in the students for making them employable and problem solvers.

Due to the current structure of the curriculum, academics generally faces difficulties in implementing new concepts, as they may tend to consider and focus on new concepts and their objectives separately. Indeed, teachers may concentrate a lot in their own area and not show interest at the learning process from a wider perspective. Even though it focuses, importantly on developing students' skills and abilities that is demanded from industry and society, as well as from students themselves.

\section{Our Approach}

In the process of curriculum review, mainly when we desire to implement changes towards a new structure of curriculum, the elements that are difficult to deal are training students to improve their skills and abilities. Skills are usually referred as transferable and incorporate continuous learning abilities. The elements which are commonly documented, still they have proven difficult to implement with regard to the functional levels, as the concentration is generally on science and conventional technical issues. The better of the two is considered in our proposal. One of them is the duration and the other being the assessment criteria.

Restructuring of curriculum should embed securing vertical and lateral coherency for the technical and scientific content. Here mainly, the additional aspect is how to find enough time for the project work, and training gaps must be dealt. Which often leads to review the curricula and rethink of their overall objectives with respect to new skill based project oriented structure. This approach can be tough as lecturers have been brought up with the common way of teaching and learning that is based on lectures.

The duration of the semester is of 6 months in which traditional teaching is for 3 and a half to 4 months, the rest for examinations and vacations. We are here proposing a maximum of 9 to 10 months duration in which 5 or 6 courses are handled. These are based on the standards that deal with the basics, historical developments and applications in the industrial perspective.

Each course is divided in to units and after the completion the students are given projects based on the level of difficulty. The duration of which is again on the course and its importance. A group of students will have to perform and the assessment is graded. There are going to be 5 to 10 projects in each subject which are to be incorporated in the curriculum design at the starting of the course and this needs a continuous updating as per the industrial needs.

The overall assessment of the course at the end is done based on a comprehensive evaluation by a group of faculty. This brings out the capability, knowledge and skill of the students and makes them industry ready which fulfills the outcome of the course.

Methodology:

- Year wise course structure( 9 to 10 months).

- Courses per year (5 to 6).

- Projects per course (5 to 10), Duration of each varies depending on the level of analysis. Prototype or simulation or programming or case studies etc., can be demonstrated for the assessment.

- Grading (60 percent weightage).

- Overall assessment (40 percent weightage).

\section{Skill-based Learning}

Skill based learning can also be referred as 
learning through practice, learning by working, learning through experience, and learning through discovery and exploration. The key element of it is self motivated and student centric learning.

In the present day scenario most of the college faculty teaches by lecturing. Although an effective lecturing should be part of a teacher's teaching collection, teachers should also actively involve their students in the learning process by means of group work, hands-on practice, and applying knowledge outside the classroom. This process defines skill based learning where students are involved in learning content in which they have a self motivation and personal interest.

A. List of Learning Principles in our Approach Unlike the classroom situations where students remain uninvolved or unmotivated and where the instruction is highly structured, students in the proposed learning situations cooperate and learn from one another in a more semi-structured approach. Instruction is designed to engage students in direct experiences which are tied to real world problems.

- Learning occurs through carefully chosen experiences that are supported by reflection, critical analysis and synthesis.

- Practices are structured to require the student to take initiation and make decisions accountable for results.

- In the learning process, the student is always actively engaged in investigating, experimenting, being curious, and solving problems, being creative and constructing.

- Students are engaged intellectually, emotionally, socially.

- Relationships are developed and nurtured: student to self, student to others and student to the world at large.

- The teacher and students may experience success or failure, risk-takings and uncertainty, because the outcome cannot be predicted.

- Opportunities are nurtured for students and instructors to explore and examine their own capabilities.

- The instructor's basic roles include setting suitable practical problems, setting boundaries to them, supporting students, and facilitating the learning process.

- The new structure of curricula includes the possibility to learn from natural consequences, errors and successes.

Learning involves a hands-on, collaborative and reflective experience which helps them to fully learn new skills and knowledge.

B. Experiencing or Doing

Students will work on the related topics given to them, gets hands-on experience with little or no help by the teachers. And come out with making products or models, role-plays, giving a presentation, problem-solving etc.

C. Reflecting "What Happened?"

Students will share the outcomes of their hands-on experiences and observations with the group members. Students will also get other members belonging to different groups to share their own experiences, observations and discuss concepts generated by the experience. The sharing of outcomes of hands-on experience reflects on what they discovered and relating it to past observations which can be used for future use.

D. Analyzing "What's Important?"

Students will analyze and reflect upon the experience. Describing and analyzing their experiences allow students to relate them to future learning experiences.

E. "So What Next?"

Students will linkup the experience with real world examples, find trends in the experience, and identify "real life" principles that emerged.

F. Application "Now What?"

Students will be able to apply what they learned in the experience to similar or varied states. Also, students will analyze how the new learned process can be applied to other circumstances. The teacher should help each student to feel a sense of right of possessing for what he was learned.

\section{Instructor Roles In Skill Based Learning}

$\checkmark$ The instructor guides rather than directs where students are naturally made interested in learning. The instructor takes the role of facilitator and is guided by a number of steps crucial to learning.

$\checkmark$ Approach the learning experience in a positive and non-dominating way.

$\checkmark$ Explain the purpose of the practical learning situation to the students.

$\checkmark$ The thoughts of teachers are shared with the students and let them know that experience gives better learning.

$\checkmark$ Bind learning objectives to course activities and administer the experiences so that students know 
what they are supposed to do.

$\checkmark$ Bestow the students with relevant and meaningful resources to succeed.

$\checkmark$ Extend the support to students to do experiments and discover solutions on their own.

\section{Student Roles In Skill Based Learning}

Students make a choice of themselves to be personally involved in the practical learning. However, the instructor takes the role of guiding and facilitates the process student learning.

- Students are involved in problems which are practical and societal.

- Students often will need to be involved with difficult and challenging situations while discovering.

- Students will evaluate themselves their own progress or success in the process of learning, which becomes the first level learning of assessment.

- Students learn from the experiences through the learning process and become ready to change. Which reduces the dependency on the instructor and more on fellow members, the development of skills to explore (research) and learn from the real experiences?

\section{Conclusion}

Skill based learning experiences help to complete student's preparation to their chosen careers and also strengthen the course content of practical implementations and theory. Students learn through experiencing the problem solving situations, work groups instead of only instructorcentered, experiences by doing, discovering, analyzing and applying. Students moving with these experiences develop practical skills, selfconfidence, and gain and strengthen decisionmaking abilities by responding to and solving real time problems and processes of the world.

\section{References}

[1] Association for ExperientialEducation, http://www.aee.org/.

[2] George Mason University. Center for Teaching Excellence (2011). About teaching Experiential learning.

http://cte.gmu.edu/Teaching/experiental_learnin g.html.
[3] Haynes, C. (2007).Experiential learning: Learningbydoing.http://adulteducation.wikiboo k.us/index.php?title=Experiential_Learning __Learning_by_Doing.

[4] Loretto, P. (2011). Learning by experience. http://internships.about.com/od/internships 101/ p/TypesExperEd.htm.

[5] Northern Illinois University, College of Business Experiential Learning Center (2011) (ELC). http://www.cob.niu.edu/elc/

[6] Northern Illinois University, Office of Student Engagement and Experiential Learning OSEEL (2011). About the office of student engagement and experiential learning (2011). http://www.niu.edu/teachercertification/teacher cert/tcp_st.shtml

[7] Northern Illinois University, Office of TeacherCertification OTC (2011).Student teaching.

http://www.niu.edu/teachercertification/teacher cert/tcp_st.shtml

[8] Northern Illinois University, Study Abroad Program SAP (2011). A parent's guide to study abroad programs.

http://www.niu.edu/studyabroad/audiences/pare nts.shtml.

[9] Wurdinger, S. D., \& Carlson, J. A. (2010). Teaching for experiential learning: Five approaches that work. Lanham, MD: Rowman \& Littlefield Education.

[10] University of California Davis (UC Davis). (2011). 5-step experiential learning cycle definitions.http://www.experientiallearning.ucd avis.edu/module1/el1_40-5step-definitions.pdf.

[11] Kari Heiskanen \& Jenni Koponen, A Skill Based Curriculum Development For Materials Science And Engineering. Joint International IGIP-SEFI Annual Conference 2010, 19th - 22nd September 2010, Trnava, Slovakia.

[12] Weerayute Sudsomboon, King Mongkut's, construction of a competency-based curriculum Content framework for mechanical technology Education program on automotive technology Subjects.

[13] A.Chuchalin, Engineering Curriculum Design Based on Program Accreditation Criteria.

[14] Paul Humphreys, Victor Lo, Felix Chan and Glynn Duggan, Developing Transferable Group work skills for Engineering Students. 